\title{
OFFICIAL LIABILITY AND ITS LESS LEGALISTIC ALTERNATIVES*
}

\author{
Mancur Olson'†
}

\section{INTRODUCTION}

Legend has it that once when Kant was out for a walk and deeply preoccupied with a complex philosophical problem, a passerby asked him the time of day. Instead of giving the expected sort of answer, Kant, in his reverie, is said to have launched into a lengthy abstract discussion of time, perception, and language. ${ }^{1}$ Most of us probably have friends or acquaintances (especially in academic life) who similarly respond to a specific issue, problem, or question with very general principles, philosophies, or prejudices rather than with points that have direct relevance to the specifics of the case. This happens to be particularly mischievous, in my experience, when intense ideological passions are brought to bear on complex and specific public-policy issues: the ideologue who avoids specifics may take a position that a careful analysis of the matter would show was inconsistent with his own values. Thus we should be wary of dealing with a specific and complex problem by invoking principles of great generality.

Yet that is what I am going to do here. The reason why I want to deal with the issue of civil liability for government officials in a very general context is that it cannot, in my judgment, be properly understood unless this is done. A physicist who studies how fast lead balls accelerate as they are released in water would surely be conscious that the relevant principles cannot be properly understood or illustrated without some attention to how objects of various sorts behave when released in the air, in a vacuum, and so on. Similarly, we should not place any confidence in a major policy recommendation unless it rests on experience in a wide variety of settings or jurisdictions, or is at least supported by a theory that has proved useful in several countries and periods.

\footnotetext{
* This article is a commentary on Mashaw, Civil Liability of Government Officers: Property Rights and Official Accountability, LAw \& Contemp. Prob., Winter 1978, at 8. It was originally presented, in a slightly different form, at the Liberty Fund, Inc., Seminar on Civil Liability and Government Officials, administered by the Law and Economics Center of the University of Miami School of Law (April 15-17, 1977).--Ed. I thank my colleague Neil Singer for his helpful criticism, though he is of course not responsible for any shortcomings of this article.-Author.

$\dagger$ Professor of Economics, University of Maryland at College Park.

1. This is the sort of story of which it is said that if it isn't true, it should be. I have only a secondary source for it, but an erudite and careful one: Professor William Parker of Yale.
} 
We must therefore ask how the suggestion that government officials should have no immunity against civil liability relates to the functions and characteristics of governments in general, or at least to our theory of government. I may seem to be putting forth a methodological requirement that is inapplicable to the law or utopian. After all, the common law of any independent jurisdiction must be a function of, among other things, the particular disputes that happened to arise, the choices that judges happened to make, and other developments that are peculiar to that jurisdiction. Similarly, what the courts ought to decide in new cases should surely depend on the statutes, which are usually unique to each country and historical period. These considerations seem to suggest that our subject is wholly encompassed by the set of institutions we are considering-that theories applicable to other societies could have no bearing on what this country should do now.

In fact, we not only can but must transcend the particular American court decisions in our analysis of the question whether government officials should bear civil liability. The issue would not have arisen in the first place if some people had not thought their interests or the interests of their clients or the interest of society, or the people, as they conceived it would be served by limiting or eliminating official immunity. An institution should surely be assessed by its capacity to serve the interests of some individuals or groups, however difficult it may be to aggregate the interests of the individuals or groups in a jurisdiction. When we start this assessment with human needs or interests, it immediately becomes clear that we can eliminate problems in the given legal system by seeking alternative ways of meeting the needs that system serves; there may be a way of meeting those needs that doesn't involve the legal system in any significant or troublesome way. For example, the solution to the problem of finding an objective judicial standard for what pornography is may be to repeal the laws against it; the way to prevent public officials from being negligent or malicious in dealing with applications for certain licenses may be to open up the restricted activity to anyone who posts a bond sufficient to compensate victims of malpractice. Similarly, if people in one jurisdiction or historical period have an aspiration or interest, the odds are that it has existed in other places and periods too; so we may be able to learn a lot from a general theory of the processes through which those aspirations and interests can be served. Useful as Jerry Mashaw's account of American court decisions is, ${ }^{2}$ we cannot tell how best to deal with official neglect or misconduct until we have seen the recent U.S. legal history in a broader context.

2. Mashaw, Civil Liability of Government Officials: Property Rights and Official Accountability, LAw \& Contemp. Prob., Winter 1978, at 8, 14-22. 
The problem at issue in this symposium, and the one that Jerry Mashaw has written about, is misbehavior or neglect by officials, not misbehavior or neglect by governments. In one sense this is a meaningless distinction, since the government has no existence apart from the actual or prospective acts of its officials. Still, there is another sense in which this distinction must be emphasized and reemphasized, because the remedies for misbehavior or neglect by governments and by officials are vastly different. We cannot prevent governmental mischief or neglect by dealing only with the mischief or neglect of officials; the government can change the laws-and with enough time and support, the constitution-so that officials who do wrong or neglect wrongs are only doing their legal duties. Indeed, if the government is wrong, official misconduct or neglect may be a remedy. Obviously, we must not jump from observing wrongs that individuals may suffer from the actions or inactions of the government's agents to the erroneous conclusion that abolishing official immunity will necessarily help. In any civilized society under the rule of law, a government official should not be punished for following the law: the law itself may be the cause of the action or inaction that we believe to be unjust, immoral, in violation of human rights, or responsible for egregious inefficiency.

Mashaw explicitly makes the distinction between the shortcomings of officials and those of governments at several points. He says, "the real culprit may indeed be sovereign, not official, immunity," 3 and related assertions appear in several different places. Even so, they do not appear often enough or in quite the right way. On occasion the implications of the distinction are obscured, as when he tells of cases where "the failure to hold the government or its officials liable seems strange." ${ }^{4}$ Nonetheless, Mashaw reasonably enough does not deal with sovereign immunity or with other arrangements that determine whether and to what extent the government compensates those whom it damages.

It would take us far afield to analyze these matters here. However, when the government makes decisions about compensation for many matters-such as special aid for school districts next to federal installations or for those who are hurt when floodwaters cross government levees or when redundant military bases are closed-it frequently seems to many of us to overcompensate the losers. It might be argued, for example, that federal projects for regions subject to flooding, and the compensation paid to the victims of the flooding that occurs when the flood-control measures are insufficient, encourage more people to live in the flood plains, thereby increasing the total social losses

\footnotetext{
3. Id. at 27.

4. Id. at 14 .
} 
from floods. As a general principle, any generous compensation of those who lose because of government action will encourage individuals to put themselves in positions where they are likely to be eligible for the generous compensation. Thus, though it may be true that official immunity and other arrangements make the U.S. government on balance deficient in compensating those whom it injures, the deficiency of compensation can by no means be taken for granted.

II

If the three foregoing conclusions-or even the first two-are correct, it follows that Mashaw's paper and this symposium are in essence about how to make bureaucrats do better work and how to provide the compensation that should be given to the victims of inadequacy in their work. The elimination or limitation of official immunity may sometimes combat the laziness, incompetence, prejudice, or inefficiency of government employees; it may also compensate those who are harmed by these inadequacies. There are no other major purposes for which official liability could possibly be the optimal instrument. Accordingly, the abolition or restriction of official immunity should be compared with alternative arrangements, including those outside of the courts, that can improve the performance of government employees or provide appropriate relief to those who are harmed by poor official performance.

The merit of this formulation of the problem can be seen by making the counterfactual but instructive assumption that a government had perfect information about what each of its servants did or didn't do. Under this assumption, all we would need to do to solve the problems that official liability is supposed to solve is to insure that any individuals or groups who are harmed by the government or its officials could receive the appropriate redress from the relevant government department rather than from its employees. If the harm were an undesirable but inevitable by-product of the carrying out of a duly passed law, and no official had erred, there could still be relief for the injured individuals; of ficial liability, by contrast, could in no way provide relief in such cases. If, on the other hand, an individual or group were injured by errors of commission or omission by an official, there would still be no need to restrict official immunity. Since, by assumption, we have worked out arrangements which allow the injured to be compensated appropriately by the offending department, and have stipulated that the government has knowledge of every sparrow's fall in the bureaucracy, we can conclude that each department has both the incentive and the capability to induce each official to behave appropriately.

In this artificial context it becomes obvious that letting the courts punish bureaucrats who err on the job would be like putting two captains in charge of the same ship: it would give the head of a department nominal responsibility for what goes on but leave the discipline of his subordinates partly up to 
the judge. To be sure, the assumption of perfect knowledge by superiors of their subordinates is wildly unrealistic, and that gives some of the implications we have drawn from it a disturbing ring. It doesn't follow from the fact that limitation of official immunity would be pointless under this assumption that it would be pointless in the real world. All that our argument from perfect bureaucratic knowledge has shown is that the elimination or limitation of official immunity is worth considering only because of the imperfections of other mechanisms for guiding the behavior of subordinates in a bureaucracy; if these other mechanisms were perfect, there would be no point in limiting official immunity. This is perhaps a narrow point, but it enables us to probe down to the very taproot of the case against official immunity.

\section{III}

If the elimination or restriction of official immunity is not the proper method of serving any significant social purpose in a world in which the head of a department has perfect information about the actions and opportunities of all subordinates, then we must look to the difficulties of getting information about subordinates in a bureaucracy as the soil in which the case for official liability might grow. The difficulty in getting information about the performance of subordinates in typical government bureaucracies has not been properly understood, in this writer's opinion, because a basic theory of the matter has only lately begun to be developed. There are serious, special problems in getting information about the effectiveness of most government agencies, their employees, and their procedures, and these special problems follow ineluctably from the character of the social purposes for which governments are needed.

It would take much more space than is available here to demonstrate fully why there are special difficulties in getting information on the performance of government officials and agencies. The explanation of the special difficulties, moreover, has been and is being set out elsewhere, for those who are interested in a complete analysis of the matter. ${ }^{5}$ Thus only a brief, intuitive, and impressionistic version of the argument will be set out here. It is not possible to follow my argument, however, without first understanding a couple of well-established ideas from my discipline, economics. Since those who specialize in other fields, such as the law, would normally have no occasion to come upon these ideas, I shall try to explain them briefly below.

Government action is necessary only to achieve those social purposes that have the character of public goods. A good is public if it meets either of the following sufficient but not necessary conditions:

5. See Olson, Evaluating Performance in the Public Sector in National Bureau of Economic Research, The Measurement of Economic and Social Performance 355 (M. Moss ed. 1973); See also Olson, Beyond the Measuring Rod of Money (forthcoming). 
1. If the good is available to one member of a group, it is available to the others, or at least cannot economically be denied them.

2 . If provided to one member of a group, the good can be provided to others at no extra cost, or at least at an extra cost that is below the average cost of all the units provided. In the language of economics, the marginal cost of the good is less than its average cost at the socially optimal level of provision.

When the first sufficient condition obtains and the group is sufficiently large, the good will not be supplied adequately, if at all, through voluntary or market behavior. Since supplying the public good to one member is tantamount to supplying it to the entire group, and since the group is, by stipulation, very large, a typical individual will get only a minuscule share of the total benefit from any unit of the public good he purchases, though he will pay the full cost of that unit. The fact that any amount of the good that is provided goes automatically to everyone in the group also means that each individual will get the benefit of any amount that has been provided by others, whether or not he has paid for any of the public good himself. This in turn means that the purchase of a unit of the public good by one individual will not give others an incentive to follow suit; rather it will partially satisfy their needs for the good. An individual may make his contribution contingent upon the contributions of others or bargain in other ways with other members of the group; but if the group is sufficiently large, a pair of individuals will not get enough benefit from combined action to justify even the relatively small costs of bargaining with each other, and more costly multilateral bargains will also be uneconomic. The only condition under which there is a high probability that an individual will voluntarily provide a public good is if the value of a unit of the good to him alone is so great that it exceeds the total cost of providing the unit to the whole group. Obviously, even if an individual provides some of the good on this ground, he will cease to provide it as soon as the cost of additional units is no longer outweighed by the benefit that he alone would derive from them-long before a socially efficient level of provision has been reached. A socially efficient level would be attained only if provision did not cease as long as the cost of additional units were outweighed by their aggregate benefit to all who would receive them. In the language of my trade, the socially optimal level of provision is attained only when marginal social cost (the cost of an additional unit) equals marginal social benefit (the aggregate benefit of an additional unit). Nothing close to this level will be provided unless compulsory payments, such as taxes, are used to obtain the resources for public goods. Thus law enforcement, defense, and pollution abatement, all of which satisfy our first sufficient condition, are normally provided only by governments, which have the power to levy taxes. ${ }^{6}$

6. This argument is explained more precisely in Olson, The Logic of Collective Action (1965). 
When the second sufficient condition obtains, markets will again fail to provide a socially efficient amount of a good. Social efficiency would, as we have seen, require that level of output at which marginal social cost equals marginal social benefit. In the absence of other problems, the value of an additional unit of a good will be measured by the price people pay for it. This holds even if the price is zero, since individuals have an incentive to continue using free goods until the marginal unit adds nothing to satisfaction. When the second sufficient condition applies, the price or average revenue at the socially optimal level of production must be less than the average cost, so that a business operating at this level of production must lose money. There is accordingly a reason to consider public subsidy or provision of goods that meet the second condition, in order to absorb the losses incurred by the producer at the socially optimal level of production.

Roads and bridges that do not suffer congestion are classic examples of goods that meet the second condition and are therefore financed out of tax revenues and provided to users free of charge. If the owner of a bridge charged each driver only what it cost to let that driver cross-i.e., practically nothing-he would never recoup the enormous expense of building the bridge. In order to recoup that expense, the bridge owner will have to divide it equally among all the toll-payers-i.e., set his price equal to his average cost. At this higher price, drivers will cease to purchase additional crossings long before the additional cost of those crossings-which is practically nothingceases to be outweighed by their additional benefit. Hence the socially optimal level of provision will not be reached.

Of course, governments sometimes intervene when no public goods are at issue, as when they nationalize firms or industries that are not significantly different from others in the private sector. However, government intervention in the production of public goods is far more common. When government intervention takes place in the absence of public goods, moreover, there is presumably no need to handle civil liability any differently from the way it is handled for private corporations. The government can provide that a public corporation can sue and be sued in much the same way as a private corporation, and can give the officers of a nationalized firm the same powers over their subordinates as officers of private firms have. Something like this appears to have been done in some nationalized industries in Europe.

\section{IV}

We are now in a position to tackle the question how a government can get information about the productivity or effectiveness of the resources it is using to produce public goods. That is, we can ask how a government gets information about the "social production function," i.e., the quantitative specification of the relation between the inputs and the output of a public or collective good. Since these relations, like any causal relations, can be determined only 
empirically, the government agency must either use controlled experiments to determine these relations or rely on a statistical analysis of the "natural experiments" that occur because of variations over time and space.

The cost of experiments and the informativeness of actual experience are, however, vastly different for private and public goods. The relationships between, say, the amount of fertilizer applied to a field and its yield of peanuts can be determined with reasonable accuracy by applying different amounts to perhaps less than a hundred tiny plots. The total cost of the experiment may be negligible in relation to the total value of the information gained, since the results of the experiment on the tiny plots are applicable to an entire industry. The total cost of the experiments divided by the total value of the information $^{7}$ will normally yield a small fraction for private goods and may even approach zero. Even if there are no controlled experiments, the fact that each peanut farmer or, indeed, each field offers an additional empirical observation will make actual experience relatively informative.

Now let's ask how we estimate the production function of a good that meets the first of the two sufficient conditions for public goods. Since, by definition, the units produced for one member of a group go to everyone in the group, every experiment with such a good must involve the entire group. If the French government of the 1930's wonders whether to rely mainly on tanks and planes or a Maginot line for its defense, it is asking an empirical question. The only way to get definite information on this question is to try each of the proposed alternatives - to have at least one war using each of the strategies. Such experiments are costly indeed. For public goods meeting the first sufficient condition the cost of an experiment is equal to the cost of providing the good for one period, since-by definition-an experiment on a scale smaller than the size of the group which receives the good automatically if any of its members receives it is itself impossible, or at least uneconomic. Over time and across countries there are some variations that amount to natural experiments; but since each group or country offers only one observation per period, historical and geographical variation is much less informative about these goods than about private goods.

Goods that meet only the second sufficient condition for public goods are characterized by much the same costliness of information. Once such a public good has been provided to one individual, the cost of providing it to others is, by definition, zero, or at least below the average cost. This can only be because there are huge fixed costs that must be met before even one unit can be produced. An example would be a bridge in an area so sparsely settled that it would never be congested. If even one person is to cross the bridge, it must be built; but then others can cross it at no cost to society. An experiment on

7. This includes the discounted present value of the use of the information over several future years. 
how bridge availability affects traffic patterns is costly because it requires the experimenters to spend almost as much as it would cost to build a nonexperimental bridge. This costliness also reduces the number of observations that historical or cross-sectional research can give us.

The greater cost of experiments to determine the production functions of public goods and the lesser informativeness of experience with these goods mean that the production functions of public goods are systematically less well known than those of private goods. Since, typically, less is known about how much of a public good could be produced with a given amount of resources used at maximum efficiency than is known in the case of private goods, less is generally known about how well a government agency is performing its mission than about how well a business is doing its job. We don't know what is par for the course so we don't know whether a given score is a good or a bad one. Indeed, in the case of public goods that satisfy the first sufficient condition (as the most basic and important public goods do), we don't even know what the score, or quantity of output is, much less what output should be expected. The very indivisibility that makes a public good go to everyone in a group in essence makes it unquantifiable. Thus, we usually don't know how much output an agency has produced, or if we knew, whether that level of output would reflect efficient management of the resources. Given these difficulties, it is no wonder that there are so many complaints about inefficiency in both civil and military branches of government, here as well as abroad: the information needed for efficient management is not available. It is also no wonder that ideology plays such a large role in views about government, since ideology thrives where definite knowledge is lacking.

$\mathrm{V}$

Whether an institution produces a divisible, private good or an indivisible, collective good affects not only our information about its overall performance and that of its manager but also its own internal processes. The more accurate the information about the output of an institution, the greater the ability to estimate the usefulness of its component parts. If changes in the dependent variable (i.e., output) are not known, there is not even a hope of estimating the contribution that each independent variable (i.e., each input) has made. But in a firm producing private goods the output, at least, is known, and there is then often the possibility of roughly apportioning the responsibility for it among the different parts of the firm. That is not only because of the rough inferences that may sometimes be drawn from time-series data or experiments but also (and more importantly) because the contribution of each part of a firm can often be measured directly. The multiproduct or geographically dispersed firm can often set up what the accountant calls profit centers to facilitate evaluation of subordinate divisions and managers. If the firm's output is at all homogeneous, it can simply count the units or components produced or 
handled by each factory or work group and relate the totals to the resources that were used. Indeed, it is often possible to tell which nut tighteners have tightened the most nuts and to pay them accordingly, that is, to use a piecerate or commission system. The fact that a piece-rate reward system is often used by firms providing private goods but usually cannot be used (except at early stages of production) by institutions providing collective goods is entirely consistent with the argument that is being made here, and suggests that the argument can have profound implications for the procedures and incentives within an institution.

The lack of readily countable outputs in jurisdictions or agencies that produce collective goods, and the resulting lack of objective bases for judging performance, have led to complicated, cumbersome, and expensive restrictions on public management. Civil-service or merit systems, requirements for competitive bidding even when bidding is evidently uneconomical, separate resource constraints for personnel, money, and certain classes of supplies, and red tape in general are the natural concomitants of immeasurable outputs and unknown production functions. Presumably, no one would care very much whether the police commissioner gave a good job to his nephew or bought uniforms from his brother if the police department were demonstrably as efficient as it could be. But since we don't know whether the police department is giving good value, we know that the commissioner could get away with hiring his nephew, however incompetent, or buying his brother's uniforms, however costly, if we didn't outlaw it directly; so we do. Civil service rules, competitive purchase provisions, and red tape no doubt prevent some of the chicanery that the lack of knowledge of actual and potential output allows; since such regulations limit the extent to which resources can be diverted from public purposes, they may even increase output at times. But they also impose enormous costs. In some cases the labyrinth of restrictions that limit the freedom of action of public administrators is so elaborate that it prevents timely action and creates a tendency to rely on contracts with outside suppliers (sometimes nonprofit firms) to get the job done. This can be only a temporary solution, since the lack of information allows inefficiency and corruption on the part of the contractors and thereby leads to regulations that hem them in as well.

The fact that it is the lack of an adequately measured output, rather than any other factor, that mainly accounts for the cumbersome regulations characteristic of government bureaucracy is also demonstrated by the tendency of nationalized industries producing private goods to have fewer regulations (at least in some countries) than civil service department providing collective goods. ${ }^{8}$ This in turn illustrates a point that must be emphasized: it is not

8. To the extent that the bureaucratic ethos has imposed some civil-service-like regulations 
governments that are inherently inefficient but rather the provision of collective goods and the handling of externalities, whether by governments or other institutions.

The difficulty of weeding out the inefficient and rewarding the efficient in institutions providing collective goods creates some problems that tend to grow worse. The criteria for promotion cannot include productivity when the volume and value of output are not known. Managers may have some intuitive impressions about output, but these are likely to be so hazy and contradictory that other considerations must in large part determine who rises in the organization. These other considerations may be very diverse. Whatever they are, talented people will be more likely to rise than stupid ones, since they will be able to find out sooner what has to be done to get promoted, and will be able to do it better. One consideration that apparently affects promotion in organizations producing collective goods is loyalty to the organization, its leadership, its ideology, and its established way of doing things. Bureaucrats with such loyalty will not rock the boat. In military organizations, police forces, fire departments, foreign ministries, and churches, at least, it of ten seems to be the consummate organization man who rises to the top. Such men, however able, tend to be conservative in the sense that they are convinced that the organization's hierarchy and practices are sound. Where it is not productivity but able and unwavering adherence to the established policy that leads to promotion, an organization is likely to depart further from ideal allocations as time goes on; the more conditions change, the farther its initial policies will be from the ideal.

\section{VI}

We can now bring together the conclusions of the different parts of the argument. We saw earlier that if heads of governments had perfect information about their subordinates' actions and options, there would be no point in limiting official immunity: the purposes of official liability could be achieved far better by letting the government itself compensate those whom it injures and determine the rewards and penalties for those whom it employs. Any other arrangement would weaken the chain of command. We then went on to show not only that there is imperfect imformation about what the government and its employees do but also that this information is systematically far worse than our information about private goods, because of the inherent characteristics of public goods. Even the special characteristics of civil-service merit systems, competitive bidding rules, and red tape derive from the informational disparity that has been described.

and personnel policies on nationalized industries, they should be less efficient on average than private enterprises. 
What has been said does not provide a basis for a decision about whether or how official immunity should be limited, but it does provide a better framework for debating the issue. It is already clear that proposals to limit official immunity are intellectually admissable, since the government's knowledge of its employees' behavior and opportunities is so poor. There is no basis whatever for the assumption that if we could somehow put the right incentives or instructions before the government as a whole, we would prevent the negligence, malice, or ineptness of government officials.

So any plausible proposal, such as the limitation of official immunity, for improving the incentives facing individual public employees deserves an early listing on the political agenda. Moreover, civil service rules already limit supervisors' control of subordinates (e.g., by making it very difficult to fire them), as a way of keeping supervisors from political favoritism or the other forms of misappropriation they could otherwise get away with in the dark continent of the bureaucracy. We may therefore have little or no objection to intrusion by the courts. The courts are, relatively speaking at least, nonpartisan and often even disinterested. We may want them to pry into the bureaucracy on occasion and to discipline those they believe to be at fault. The aggrieved individuals who bring action can be regarded as socially costless inspectors who bring us information that we need about the shortcomings of bureaucrats simply as a byproduct of their efforts to protect their own rights. Clearly there is a case for some types of official liability.

But our framework also shows that the elimination of official immunity cannot solve the problem of the inadequacy of bureaucracies and indeed cannot even touch the largest part of that problem. To determine whether a government official is doing his job adequately a court would have to know not only what he has accomplished (which usually can't be found out) but also what he could have achieved (which can only be discovered once the production function is known). The courts have no magic way of estimating production functions; indeed, their largely nonquantitative methods for getting evidence are probably especially ill-suited to the estimation of production functions. To consider an especially simple and typical case, suppose we allowed a citizen who has been robbed to sue the police chief or the cop on the beat, on the ground that they are not providing the protection they should provide. We know that the best policemen cannot prevent all crime, and we can usually take it for granted that civil service regulations will insure that the policemen are not using the police budget to buy booze or hire relatives. Thus, there is usually no way to assess such a complaint without making a quantitative estimate of what the police have achieved in reducing the crime rate and then comparing this with what could have been achieved with an optimal allocation of the police budget. The very idea of a trial in which this is attempted strains the imagination.

There is also the point that courts consider only the rights of the individu- 
als who come before them, whereas government officials affect the interests of individuals as well as their rights. My interests are best served if the Chief of Staff of the U.S. Armed Forces is as smart as Clausewitz, because I will then be more relaxed and feel more secure from foreign invaders. But I don't have a right to such a Chief of Staff that I can regularly protect in the courts, in the way I have a right to make speeches critical of General Brown or a right to trial by a jury if a prosecutor wants to incarcerate me for various offenses. Since many of the shortcomings of government officials affect the interests of citizens rather than any specific or well-defined rights, it is difficult to see how the courts would deal very well with them. ${ }^{9}$

Then, finally, there is the familiar point that our country uses the courts far too much anyway, and shouldn't burden them with yet another set of tasks. For good reasons or bad, we do not put a price on the use of the courts or even on appeals of the decisions of lower courts. I am told by friends in the law that when a case is appealed by a defendant, the appeal can normally result in a reversal of the earlier decision but not in a heavier penalty if the initial decision is upheld. When appeals cost the defendant so much less than they cost society, they are probably overused. Any economist would predict that the result of free access to the courts, and of the policy that almost any type of grievance can be taken to the courts, would be overloaded dockets, ridiculously long queues, excessive plea bargaining, and an ever-increasing number of lawyers. Thus the proponents of limitations on official immunity must show how the courts would handle the extra burden and how much it would cost in money, in delays, and in the neglect of other types of cases. They will not, I suspect, find the answers to these questions reassuring.

9. See George Stigler's humorous article on the problems that would be caused by allowing students who were hurt by untruthful teaching to sue for damages. Stigler, A Sketch of the History of Truth in Teaching, 81 J. Political. Econ. 491 (1973). 